\title{
The evaluation of scabies management in children at tertiary referral hospital in Surabaya
}

\author{
Mochammad Ayyub Arachman ${ }^{\mathrm{a}}$, Iskandar Zulkarnain ${ }^{\mathrm{a}}$, Sawitria ${ }^{\mathrm{a}}$, Afif Nurul \\ Hidayatia ${ }^{a}$ Cita Rosita Sigit Prakoeswa ${ }^{{ }^{*}}$

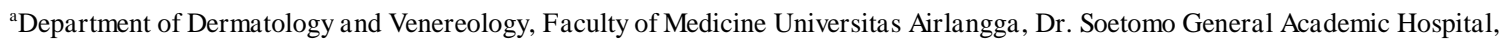 \\ 60286, Surabaya, East Java, Indonesia \\ *Email: cita-rosita@fk.unair.ac.id
}

\begin{abstract}
Scabies is still a health issue in the majority of developing countries. Scabies in children may cause harm and sepsis if not treated properly. With these issues in mind, this study aims to describe and evaluate the management of scabies cases over the course of four years using a retrospective descriptive study supported by pediatric patients with a scabies diagnosis recorded in their medical records at the Dr. Soetomo General Academic Hospital Surabaya's Division of Pediatric Dermatology-Venereology Outpatient Clinic from 2015 to 2018. Male have outnumbered females by a large percentage (63.7\%) since the 2015-2018 visit (36.3\%). Scabies children, on average, have a history of infection, with the main family origin accounting for around 370 cases $(75.4 \%$ ), while those without a source of transmission account for up to 60 children $(12.2 \%)$. Scabies affects male patients aged 5 to 14 years, causing itching, especially at night. Permethrin 5\% topical scabicide was the most common treatment for scabies sufferers at Dr. Soetomo General Academic Hospital in 2015-2018, with 395 children receiving it $(80.45 \%)$. Scabies management with scabicide administration revealed that $72(39.8 \%)$ scabies with secondary infection and $3(1 \%)$ scabies without secondary infection were not treated with scabicide. We recommend the health personnel follow the guidelines for scabies treatment with and without secondary infection and carefully record it in the medical record.
\end{abstract}

Keywords: Scabies; children, dermatology; skin management

\section{Introduction}

Scabies is a skin disease in humans caused by the mite Sarcoptes scabiei, which makes burrows in the skin and is transmitted through personal contact (Romani et al., 2015). Scabies infestation harms the patient's quality of life. Complaints of itching at night often interfere with the patient's sleep quality, damage the epidermis due to the process of scabies digging for mites, and skin damage caused by scratching and excoriation as an entry point for pathogenic bacteria. In prolonged scabies infection, eczematous skin changes are more dominant, so the risk of bacterial infection increases. The development and transmission of skin infections caused by streptococcal infections caused by scabies are thought to be influenced by hygiene (McCarthy et al., 2004).

Scabies is still a health problem in most poor and underdeveloped countries (Walton and Currie, 2007). Children in developing countries are most susceptible to this disease, with a prevalence of about 5-10\%. Poverty and overcrowding are the main risk factors, and transmission is general in a community and refugee camp. A systemic review conducted by Romani and colleagues on 48 studies of scabies, showed that the highest prevalence was in Papua New Guinea, at 71\% (Romani et al., 2015). Scabies in children can cause sepsis and lymphadenopathy, acute post-streptococcal glomerulonephritis, and rheumatic fever (Ibrahim et al., 2015; Thomas et al., 2015). 
Scabies affects about 100-300 million patients worldwide, but accurate prevalence rates are difficult to determine. Scabies can occur at all ages, races, and socioeconomic levels (Thomas et al., 2015). In developing countries, scabies is found sporadically in a community. In the UK, scabies had a prevalence from 1997 to 2005 of 2.81 per 1000 in women and 2.27 per 1000 in men. In Chile, the prevalence of scabies is $1-5 \%$. A study at a hospital in Cairo, Egypt, showed that scabies is a disease that is often found, with a percentage of $9.26 \%$ of all skin diseases. A study at an orphanage in Malaysia on 120 children, found that $46 \%$ had scabies at the age of 10-12 years (Fuller, 2013). According to the Ministry of Health of the Republic of Indonesia, scabies was the third most common skin illness in Indonesia in 2008, with a prevalence of 5.6-12.95 percent based on data from health centers around the country. A retrospective study conducted by Kartika Paramita in 2009-2011 at the Outpatient Clinic for Dermatology and Venereology, Dr. Soetomo General Academic Hospital, Surabaya, showed the prevalence of scabies in children was $5.9 \%$ of all patients in the pediatric dermatology division (Paramita and Sawitri, 2015).

The clinical features of classic scabies should lead to a diagnosis. However, clinical infestations can produce a variety of appearances. Patients with secondary infection and mild to severe eczematous changes may present with atypical symptoms. Untreated scabies is often associated with pyoderma, mainly due to secondary invasion by S. pyogenes. Such infections can lead to cellulitis, ulcers, or lymphangitis (McCarthy et al., 2004). Due to the sores are unpleasant, sensitization to the fluids and secretions of the scabies mite can cause discomfort. As a result, patients often scratch and lead a secondary infection, especially those caused by Group A Streptococci (GAS) and Staphylococcus aureus. Complications caused by secondary infestations of GAS and S. aureus are common in children in developing countries (Anggreni and Indira, 2019). Epidemiological studies have shown an association between epidermal infestations with S. scabiei and bacterial skin infections (pyoderma, impetigo), especially in the tropics. Secondary bacterial skin infections commonly associated with scabies infestations are mainly caused by two clinically crucial pathogens, namely Streptococcus pyogenes and Staphylococcus aureus (Swe et al., 2014).

Scabies is a simple disease to treat, but because it is not life-threatening, it is overlooked frequently, resulting in inadequate treatment or a prolonged infestation (Mutiara and Syailindra, 2016). The prevalence of cases is still among the most common skin diseases, especially those accompanied by secondary infections, so research is needed to evaluate the management of scabies. This retrospective study was conducted to evaluate the management and characteristics of scabies patients in the Division of Pediatric Dermatology-Venereology Outpatient Clinic, Dr. Soetomo General Academic Hospital Surabaya for the 2015-2018 period.

\section{Methods}

The research design used in this study was a retrospective descriptive study, supported by pediatric patients with a diagnosis of scabies recorded in the medical record at the Division of Pediatric DermatologyVenereology Outpatient Clinic, Dr. Soetomo General Academic Hospital Surabaya for the 2015-2018 period. The sample of this study was calculated using total sampling sourced from secondary data, specifically medical records from the Division of Pediatric Dermatology-Venereology Outpatient Clinic, Dr. Soetomo General Academic Hospital Surabaya period January 2015 - December 2018. This study was obtained ethical clearance and approved by Clinical Research Unit from the Ethical Health Committee of Dr. Soetomo General Academic Hospital Surabaya Number 1751/KEPK/2020. Data were processed descriptively using Microsoft Excel 2016 software and data analysis using SPSS 26 program. Mann-Whitney U tests were used to analyze the difference between non-parametric variables. 


\section{Results}

A total of 491 medical records with a diagnosis of scabies in pediatric patients were collected from January 2015 to December 2018 with details of 120 pediatric scabies patients in 2015, 99 participants in 2016, 152 children in 2017, and 120 participants in 2018 occurred in children aged 5 to 14 years in about 320 patients $(65.2 \%)$. Since the $2015-2018$ visit, boys outnumbered girls $(63.7 \%)$ by a wide margin $(36.3 \%)$. Scabies children, on average, have a history of infection, with the dominant family origin of roughly 370 cases $(75.4 \%)$, while those who do not have a source of transmission with scabies disease number up to 60 patients (12.2\%). Other clinical characteristics are presented in Table 1.

Table 1. The Clinical characteristic of participants $(\mathrm{N}=491)$

\begin{tabular}{|c|c|c|c|c|}
\hline \multirow[t]{2}{*}{ Variables } & \multicolumn{4}{|c|}{ Year } \\
\hline & $\begin{array}{r}2015 \\
\mathrm{~N}(\%) \\
\end{array}$ & $\begin{array}{r}2016 \\
\mathrm{~N}(\%) \\
\end{array}$ & $\begin{array}{r}2017 \\
\mathbf{N}(\%) \\
\end{array}$ & $\begin{array}{r}2018 \\
\mathbf{N}(\%) \\
\end{array}$ \\
\hline \multicolumn{5}{|l|}{ Age (y.o.) } \\
\hline $0-1$ & $12(10)$ & $16(16.2)$ & 15 (9.9) & $19(15.8)$ \\
\hline $1-4$ & $29(24.2)$ & $23(23.2)$ & $34(22.4)$ & $23(19.2)$ \\
\hline $5-14$ & $79(65.8)$ & $60(60.2)$ & $103(67.8)$ & $320(65.2)$ \\
\hline \multicolumn{5}{|l|}{ Gender } \\
\hline Male & $82(62.9)$ & $67(62.9)$ & $90(62.9)$ & $74(62.9)$ \\
\hline Female & $38(37.1)$ & $32(37.1)$ & $61(37.1)$ & $46(37.1)$ \\
\hline \multicolumn{5}{|l|}{ Transmission history } \\
\hline Family & $95(79.2)$ & $74(74.7)$ & $112(73.7)$ & $89(74.2)$ \\
\hline Boarding school & $11(9.2)$ & $11(11.1)$ & $17(11.2)$ & $12(10)$ \\
\hline Neighbors & $2(1.7)$ & $3(3)$ & $2(1.3)$ & $3(2.5)$ \\
\hline None & $12(10)$ & $11(11.1)$ & $21(13.8)$ & $16(13.3)$ \\
\hline \multicolumn{5}{|l|}{ Skin Scraping test } \\
\hline Positive & $12(10)$ & $0(0)$ & $4(2.6)$ & $1(0.9)$ \\
\hline Negative & $15(12.5)$ & $4(4)$ & $8(5.3)$ & $7(5.8)$ \\
\hline No data & $93(77.5)$ & $95(96)$ & $140(92.1)$ & $112(93.3)$ \\
\hline \multicolumn{5}{|l|}{ Diagnose } \\
\hline Scabies & $71(22.9)$ & 59 (19) & $102(32.9)$ & $78(25.2)$ \\
\hline Scabies + secondary infection & $49(27.1)$ & $40(22.1)$ & $50(27.6)$ & $42(23.2)$ \\
\hline \multicolumn{5}{|l|}{ Follow-up frequency } \\
\hline Once & $48(40)$ & $24(24.2)$ & $47(30.9)$ & $13(10.8)$ \\
\hline Twice & $0(0)$ & $0(0)$ & $0(0)$ & $4(3.3)$ \\
\hline Three times & $0(0)$ & $0(0)$ & $0(0)$ & $3(2.5)$ \\
\hline$>3$ times & $3(2.5)$ & $0(0)$ & $0(0)$ & $0(0)$ \\
\hline None & $69(57.5)$ & $75(75.8)$ & $105(69.1)$ & $100(83.3)$ \\
\hline
\end{tabular}

Data were presented in number and percentage.

On skin scraping examination. there are approximately $90 \%$ of patients do not have previous data records. It does not imply that the examination is not performed; nonetheless, the results of the examination may not be recorded in the participant's medical record. Of the total 491 scabies children, most of them had a scabies diagnosis alone, namely 310 patients $(63.1 \%)$, then scabies with secondary infection were 181 patients $(36.9 \%)$. Table 2 shows the morphology of the lesions suffered by the participants. From year to year, as many as 455 individuals come for treatment with the morphology of the lesion in the form of papules (35.7\%). Then followed by lesions in the form of macular erythema in 352 patients $(27.6 \%)$, and the least excoriation was 13 patients (1\%). There were as many as 150 patients $(11.8 \%)$ who had pustule lesions and in scabies patients with secondary infection, 39 patients $(21.5 \%)$. 
Table 2. Scabies patient lesion morphology $2015-2018$

\begin{tabular}{lrrrr}
\hline Lesion morphology & \multicolumn{4}{c}{ Year } \\
\cline { 2 - 5 } & $\mathbf{2 0 1 5}$ & $\mathbf{2 0 1 6}$ & $\mathbf{2 0 1 7}$ & $\mathbf{2 0 1 8}$ \\
& $\mathbf{N}(\boldsymbol{\%})$ & $\mathbf{N}(\mathbf{\%})$ & $\mathbf{N}(\boldsymbol{\%})$ & $\mathbf{N}(\mathbf{\%})$ \\
\hline Papule & $109(34.1)$ & $87(39.2)$ & $139(35.8)$ & $120(34.9)$ \\
Pustule & $39(12.2)$ & $24(10.8)$ & $42(10.8)$ & $45(13.1)$ \\
Erosion & $51(15.9)$ & $33(14.9)$ & $41(10.6)$ & $52(15.1)$ \\
Crust & $23(7.2)$ & $11(5)$ & $17(4.4)$ & $12(3.5)$ \\
Skuama & $26(8.1)$ & $3(1.4)$ & $11(2.8)$ & $6(1.7)$ \\
Excoriations & $5(1.6)$ & $3(1.4)$ & $2(0.5)$ & $3(0.9)$ \\
Vesicle & $1(0.3)$ & $9(4.1)$ & $7(0.3)$ & $1(0.3)$ \\
Erythema macular & $109(20.6)$ & $87(23.4)$ & $139(30.5)$ & $120(30.5)$ \\
\hline
\end{tabular}

One patient may have one or more lesion morphology

One participant may have more than one therapy. Most children with scabies each year are given topical scabicid treatment $(95.11 \%)$ (Table 3 ). Topical scabicid itself consisted of permethrin 5\% cream $(80.45 \%)$ and 2-4 ointment (14.66\%), followed by oral antihistamines (91.04), which almost half used CTM. Then the third most was oral antibiotic therapy (30.83\%), topical antibiotics, namely sodium fusidate as many as 82 patients (16.70\%).

Table 3. The therapy of scabies patients in $2015-2018$.

\begin{tabular}{lrrrrr} 
& \multicolumn{2}{c}{ Year } & \multicolumn{2}{c}{ Total } & Therapy \\
\cline { 2 - 5 } & $\mathrm{N}=120$ & $\mathrm{~N}=99$ & $\mathrm{~N}=152$ & $\mathrm{~N}=120$ & $\mathrm{~N}=491$ \\
\hline Hospitalized & $1(0.83)$ & $0(0)$ & $0(0)$ & $0(0)$ & $1(0.20)$ \\
Topical scabicid & $120(100)$ & $96(96.97)$ & $137(90.13)$ & $112(93.33)$ & $467(95.11)$ \\
Oral antihistamine & $107(89.17)$ & $93(93.94)$ & $140(92.11)$ & $107(89.17)$ & $447(91.04)$ \\
Oral antibiotic & $41(34.17)$ & $32(12.12)$ & $42(7.89)$ & $41(24.17)$ & $156(30.83)$ \\
Steroid & $7(5.83)$ & $2(2.02)$ & $2(1.31)$ & $1(0.83)$ & $12(2.44)$ \\
Topical antibiotic & $11(9.17)$ & $14(14.14)$ & $31(20.39)$ & $28(23.33)$ & $84(17.11)$ \\
Others & & & & \\
$\quad$ - NaCl 0.9\% sol /Saline sol (solution) & $13(10.83)$ & $9(9.09)$ & $24(15.79)$ & $15(12.50)$ & $61(14.46)$ \\
$\quad$ - Baby cream & $1(0.83)$ & $0(0)$ & $0(0)$ & $0(0)$ & $1(0.20)$ \\
$\quad$ - Paracetamol & $3(2.5)$ & $2(2.02)$ & $2(1.32)$ & $3(2.50)$ & $9(1.83)$ \\
\hline Data were viewed as the number and percentage of total participants of each year. One patient may have one or more therapy.
\end{tabular}

Table 4 reports the clinical therapy received by children with secondary infection. The average duration of illness in most participants occurred for 14 to 30 days both in patients with secondary infection 55 participants (30.4\%) and without secondary infection as many as 107 participants (24.8\%). From the results of the nonparametric test with the Mann-Whitney $U$ test, the length of illness on the presence or absence of secondary infection in scabies has a value of $\mathrm{p}=0.376(\mathrm{p}>0.05)$ which means that there is no statistically significant difference between groups of the duration of illness with the incidence of secondary infection in scabies children. Table 4 also describes the administration of scabicid and antibiotics to participants with and without secondary infection. Approximately 142 children have registered regarding the progress result of the therapy. Of the 181 patients with secondary infection, 65 children had therapy progress records, while of 310 children with a diagnosis of scabies alone, only 77 patients had therapy progress records. Based on these findings, 60 of the 65 patients with secondary infections improved $(92.3 \%)$, whereas five did not $(7.7 \%)$. Out of 77 scabies children without secondary infection, $68(88.3 \%)$ were said to be improving, and $9(11.7 \%)$ were stated to be not improving. 
Table 4. Clinical therapy in scabies patient with secondary infection

\begin{tabular}{|c|c|c|c|}
\hline \multirow[t]{2}{*}{ Variable } & \multicolumn{2}{|c|}{ Secondary infection } & \multirow{2}{*}{$\begin{array}{c}\text { Total } \\
\text { N=491 }\end{array}$} \\
\hline & $\begin{array}{c}\text { Yes } \\
N=181\end{array}$ & $\begin{array}{c}\text { No } \\
\mathbf{N}=\mathbf{3 1 0}\end{array}$ & \\
\hline \multicolumn{4}{|l|}{ Duration of illness (days) } \\
\hline $1-7$ & $48(26.5)$ & $64(20.6)$ & $112(22.8)$ \\
\hline$>7-14$ & $33(18.2)$ & $62(20.0)$ & $95(19.4)$ \\
\hline$>14-30$ & $55(30.4)$ & $107(34.6)$ & $162(33.0)$ \\
\hline$>30$ & $45(34.9)$ & $77(24.8)$ & $122(24.8)$ \\
\hline \multicolumn{4}{|l|}{ Scabicid administration } \\
\hline Had not received & $72(39.8)$ & $3(1.0)$ & $75(15.3)$ \\
\hline Permethrin $5 \%$ cream & $80(44.2)$ & $264(85.1)$ & $344(70.1)$ \\
\hline $2-4$ ointment & $18(9.9)$ & $3(1.0)$ & $21(4.3)$ \\
\hline Permethrin $5 \%$ cream $+2-4$ ointment & $11(6.1)$ & $40(12.9)$ & $51(10.3)$ \\
\hline \multicolumn{4}{|l|}{ Antibiotic administration } \\
\hline Had not received & $28(15.5)$ & $304(98.1)$ & $332(67.6)$ \\
\hline Amoxicillin & $20(11.0)$ & $0(0)$ & $20(4.1)$ \\
\hline Kloksasilin & $57(31.5)$ & $2(0.6)$ & $59(12.0)$ \\
\hline Erythromycin & $76(42.0)$ & $4(1.3)$ & $80(16.3)$ \\
\hline
\end{tabular}

Data were presented in number and percentage.

\section{Discussion}

\subsection{Fundamental data}

Research on scabies in the Division of Pediatric Dermatology and Venereology Outpatient Clinic, Dr. Soetomo General Academic Hospital in 2015-2018 as many as 491 patients, namely 10.0\% of all Pediatric Dermatology Division patients and $0.8 \%$ of all Skin and Gender Outpatients. The same previous study by Retha in the Division of Pediatric Dermatology-Venerology Outpatient Clinic, Dr. Soetomo General Academic Hospital in 2012-2014 totaled 545 patients with scabies in children, namely $33.6 \%$ of them and $3.2 \%$ of all outpatients. There was a decrease in the prevalence of scabies from a previous retrospective study probably because the patients had been treated at other health facilities than at Dr. Soetomo General Academic Hospital.

The prevalence of scabies varies and is difficult to determine (Monsel et al., 2016; Mounsey and McCarthy, 2013). A study at a hospital in Cairo, Egypt, showed that scabies is a disease that often occurs with a percentage of $9.26 \%$ of all skin diseases. Meanwhile, a study of 120 children in a Malaysian orphanage found that 46 percent of children had scabies when they were 10-12 years old (Fuller, 2013). A systematic review conducted by Romani and colleagues on 48 studies of scabies, showed that the highest prevalence was in Papua New Guinea, at $71 \%$. Children in developing countries are most susceptible to this disease, with a prevalence of around 5-10\% (Engelman et al., 2013).

In this study, the most age group of scabies patients was in the age group 5-14 years, as many as 320 patients (65.2\%). The data are similar to the previous retrospective study by Retha in the Division of Pediatric Dermatology and Venereology Outpatient Clinic, Dr. Soetomo General Academic Hospital for the period 20122014, that the most age group is the age group 5-14 years, as many as 377 patients (69\%). Likewise in the study of Kaur and Nadeswary in Malaysia, most scabies attacks children in the 5-9 year age group (Ibrahim et al., 2015). Lassa conducted an epidemiological study of the prevalence of scabies in the UK and found the highest age group in the 10-19 year age group (Lassa et al., 2011). The possibility occurs at that age because children have not been able to maintain good hygiene. In addition, the age of 5-14 years is the age condition when children start making friends and playing outside the home and going to school, so they are more likely to be exposed to the disease from outside the home. 
Scabies patient in Division of Pediatric Dermatology and Venereology Outpatient Clinic, Dr. Soetomo General Academic Hospital Surabaya for the 2015-2018 period had more males than females. There were 313 male patients (63.7\%) and 178 female patients (36.3\%) with a ratio of $1.8: 1$. This data may be because boys are less concerned with hygiene and are more productive outside the home. Similar to the previous research conducted by Retha at the Division of Pediatric Dermatology-Venereology Outpatient Clinic, Dr. Soetomo General Academic Hospital for the period 2012-2014 found that the gender of the majority of scabies patients was $62.6 \%$ male and 37.4\% female. Lassa and colleagues in the UK in 1997-2005 showed that more women suffer from scabies (Lassa et al., 2011). Likewise, research by Marks and colleagues in the Salomon Islands showed that women suffer from scabies more than men (Marks et al., 2015). Epidemiological studies indicate that the prevalence of scabies is not influenced by gender, race, age, or economic and social status (Thomas et al., 2015).

\subsection{Clinical data}

For the 2015-2018 period, the majority of scabies patients in the Division of Pediatric Dermatology and Venereology Outpatient Clinic, Dr. Soetomo General Academic Hospital had the main complaint of itching, especially at night, with 422 patients (50.7\%). This data is similar to the results of Retha's research at the Division of Pediatric Dermatology, Outpatient Dermatology and Venereology, Dr. Soetomo General Academic Hospital from 2012 through 2014, which showed the most patients' main complaint in the form of itching, especially at night, as many as 383 patients $(70.28 \%)$. Because scabies activity is more active at night (Monsel et al., 2016), pruritus is more noticeable at night.

For the 2015-2018 period, scabies patients in the Division of Dermatology and Venereology Outpatient Clinic, Dr. Soetomo General Academic hospital revealed that 6 patients had previously suffered from scabies and experienced reinfestation (1.2\%), whereas previous research by Retha in 2012-2014 revealed all new patients, which were patients who had never had scabies before. This result may be due to the acquisition of anamnesis data in incomplete medical records regarding infestation. Reinfestation often occurs in endemic areas, because patients who have recovered from treatment are often re-infected by members of the household who have not been treated (Romani et al., 2015). Most of the scabies patients in this study had families with complaints of scabies or were suspected of being the source of transmission, namely 370 patients $(75.4 \%)$. Research by Retha also showed that patients had a family with a similar disease, as many as 362 patients (66.4\%). Following the theory that transmission of scabies is mediated by close patient contact, so it is common among family members (Thomas et al., 2015).

\subsection{Examination}

Table 2 shows the morphology of lesions of scabies patients in the Division of Division of Pediatric Dermatology and Venereology Outpatient Clinic, Dr. Soetomo General Academic Hospital 2015-2018 period. One patient may have more than one lesion morphology. Most patients had papule morphology, as many as 455 patients (35.7\%). Then followed by lesions in the form of macular erythema in 352 patients (27.6\%), and the least excoriation was 13 patients (1.0\%). These results support the theory that the morphology of scabies is in the form of papules, vesicles, nodules, excoriations, and deposits (Ibrahim et al., 2015; Monsel et al., 2016). Almost all scabies patients in the 2015-2018 period were not examined for skin scraping, as many as 440 patients $(89.6 \%)$. The statistics could be because history and physical examination are usually enough to diagnose scabies, hence skin scraping is rarely applied. In addition, skin scraping may be performed but not 
recorded in the medical record. The majority of scabies patients in this study had a diagnosis of scabies alone, namely 310 patients $(63.1 \%)$, then scabies with secondary infection as many as 181 patients $(36.9 \%)$. The morphology of pustules in 150 patients is shown in Table 2. (11.8\%). These statistics are similar to the literature that scabies can be followed by secondary infections, which are mainly caused by Staphylococcus aureus and Streptococcus pyogenes. Moreover, it can be complicated by abscess, cellulitis, necrotizing fasciitis, septicemia, renal and rheumatic heart disease (Romani et al., 2015) A systematic evaluation conducted by Romani and colleagues on the prevalence of scabies and impetigo in children revealed no significant association between the frequency of scabies and impetigo. There are areas with a high prevalence of impetigo, but a low prevalence of scabies, and vice versa. The explanation for this could be due to underdiagnosis and misdiagnosis of scabies (Romani et al., 2015).

\subsection{Management}

Table 3 displays the treatment of scabies patients in the Division of Pediatric Dermatology, the Outpatient Clinic of Dermatology and Venereology, RSUD Dr. Soetomo period 2015-2018. One patient can have more than one therapy. Most scabies patients were given topical scabicide permethrin 5\%, 395 patients $(80.45 \%)$ followed by oral antihistamines, namely CTM as many as 243 patients (49.49\%), oral antibiotics, namely erythromycin, 77 patients $(15.68 \%)$ ), topical antibiotics, namely sodium fusidate as many as 82 patients (16.70\%). These results are similar to Retha's study in the 2012-2014 period, which showed permethrin topical scabicide to be the central therapy, as many as 466 patients $(85.5 \%)$. During the period 2015-2018, one scabies patient $(0.20 \%)$ required hospitalization. Scabies can complicate bacterial infections of the skin, such as impetigo, cellulitis, and abscesses. Those infections can become more serious problems such as sepsis and more invasive infections (Engelman et al., 2013).

A review of randomized control trials by the Cochrane Collaboration concluded that permethrin is the most effective agent for the treatment of scabies (Burkhart, 2012). Antihistamines such as chlorpheniramine, hydroxyzine, diphenhydramine, and dexchlorpheniramine can be used to treat scabies itching (Ibrahim et al., 2015). Systemic or topical antibiotics may be given if a secondary infection is present (Strong and Johnstone, 2010; Thomas et al., 2015).

Most of the scabies patients generally did not come back, as many as 349 (71.1\%). A total of 132 patients came back 1 time (91.7\%), 4 patients came back 2 times (2.8\%), 3 patients came back 3 times (2.1\%), and 3 patients came more than 3 times $(2.1 \%)$. Research by Retha for the period 2012-2014 also showed that generally, patients did not come back for control, as many as 356 (62.32\%). The number of patients who did not come for control could be because the patient had recovered, or did not recover and sought treatment elsewhere. Meanwhile, patients who come for control more than twice need to be suspected of having reinfestation from their family or sources of infection who have not been treated. The importance of educating patients and families can affect the rate of return of patients for scabies control.

Table 4 represents the length of illness against the presence/absence of secondary infection in the Division of Pediatric Dermatology, the Outpatient Clinic of Dermatology and Venereology Dr. Soetomo General Academic Hospital from 2015 to 2018. It was found that scabies with secondary infection 55 (30.4\%) and without secondary infection 107 (24.8\%) were mostly found in patients suffering from illness $>14-30$ days. In a previous study, the period 2012-2014 showed that the most patients came for treatment after having symptoms of scabies for more than 30 days, as many as 282 patients $(51.7 \%)$. These statistics are related to the patient's lack of awareness about the importance of self-examination and treatment if you are experiencing symptoms. 
Scabies symptoms may appear to be moderate, causing the patient to postpone visiting a doctor. Untreated scabies is often associated with pyoderma, mainly due to secondary invasion by $\mathrm{S}$. pyogenes, and it is essential to recognize scabies as a big trigger for streptococcal pyoderma (Mounsey and McCarthy, 2013).

Scabicide therapy for the presence/absence of secondary infection in scabies patients in the Division of Pediatric Dermatology, Outpatient Dermatology and Venereology, Dr. Soetomo General Academic Hospital for the period 2015-2018 scabies with 72 (39.8\%) secondary infections and 3 (1\%) scabies without secondary infection did not receive scabicide therapy. Scabies without secondary infection not receiving scabicide therapy may be possible because they have received previous scabicide therapy from other health care centers. Patients with secondary infection who received 5\% permethrin, 2-4 ointment, and a combination of both were 80 $(44.2 \%), 18(9.9 \%)$, and $11(6.1 \%)$. Because the skin surface of patients with secondary infections is generally not intact, systemic absorption may occur, resulting in neurotoxicity. It is common in the pediatric and geriatric populations, especially when the medicine is administered excessively or on injured skin. Neurotoxic effects reported after topical application are nausea and vomiting, disorientation, restlessness, tremors, seizures, and death (Chandler and Fuller, 2019).

The administration of antibiotics for the presence/absence of secondary infection shows that $28(15.5 \%)$ of scabies with secondary infection were not given antibiotics. It is possible that the degree of secondary infection is not widespread or is classified as mild and is not followed by bacteremia or has received antibiotics before. $10(11 \%), 57(31.5 \%)$, and $76(42 \%)$. There were $4(6.25 \%)$ scabies patients with secondary infection who were not given antibiotics and controls, 3 of whom improved. Clinical improvement in these patients could be due to receiving other therapies such as scabicides. Secondary infection is a frequent complication of scabies due to disruption of the epidermal barrier caused by excoriation. The principle of treatment of secondary infection in scabies is the systemic antibiotic treatment that includes gram-positive organisms - at least 7 days. The timing of starting antibiotics depends on the patient's condition; can be started concurrently with a scabicide or delayed for 48 hours to allow partial healing of erosions. Topical antibiotics are not indicated in patients already treated with systemic antibiotics (Ibrahim et al., 2015). This study has several limitations especially the data did not provide good records, therefore the history of patient examination results and follow-up is not optimal.

\section{Conclusions}

Most of the patients were men with complaints of itching lesions in the first rank and popular lesion is the most morphology. Skin scrapping examination was not performed $89.6 \%$, this may be due to the fact that the diagnosis of scabies is considered sufficient by history and physical examination, so skin scraping is rarely performed. In addition, skin scraping examinations may be performed but are not recorded. Fifteen percenct of scabies with secondary infection were not given antibiotics. It is possible that the degree of secondary infection is not extensive or is classified as mild and is not followed by bacteremia or has received antibiotics before. We recommend the health personnel follow the guidelines for scabies treatment with and without secondary infection and carefully record it in the medical record. Provide information in the medical records regarding outpatient statuses, such as the previous history of the same disease, history of co-morbidities, lesion location, lesion morphology, and skin scraping examination. Data on clinical improvement, as well as information on recovery or the need to return for treatment as part of the treatment evaluation, must be kept on file.

\section{Acknowledgments}

The authors thank Colleagues in the Department of Dermatology and Venereology of Dr. Soetomo General Academic Hospital, Surabaya Indonesia for supporting this present study. 


\section{References}

Anggreni, P. M. D. and Indira, I. G. A. A. E., 2019. Korelasi Faktor Prediposisi Kejadian Skabies Pada AnakAnak Di Desa Songan, Kecamatan Kintamani, Kabupaten Bangli, Provinsi Bali. E-Jurnal Medika 8, p. 4-11.

Burkhart, C., 2012. Scabies, other mites and pediculosis. in In, W. K., Goldsmith, L. A., Katz, S. I., Gilchrest, B. A., Paller, A. S. and Leffell, D. J., (eds.) Fitzpatrick's Dermatology in General Medicine,New York: McGraw-Hill. pp. 4822-4840.

Chandler, D. J. and Fuller, L. C., 2019. A review of scabies: an infestation more than skin deep. Dermatology 235, p. 79-90.

Engelman, D., Kiang, K., Chosidow, O., McCarthy, J., Fuller, C., Lammie, P., Hay, R., Steer, A. and Members Of The International Alliance For The Control Of, S., 2013. Toward the global control of human scabies: introducing the International Alliance for the Control of Scabies. PLoS neglected tropical diseases 7, p. e2167.

Fuller, L. C., 2013. Epidemiology of scabies. Current Opinion in Infectious Diseases 26, p. 123-126.

Ibrahim, S. B. B. K., Ambrose, D. A., Baseri, M. B. M., Saad, H. B., Leen, W. A. and Saim, P. S. J. B. M., 2015. Guideline for management of scabies in adults and children. Ministry of Health Malaysia 1-15.

Lassa, S., Campbell, M. J. and Bennett, C. E., 2011. Epidemiology of scabies prevalence in the UK from general practice records. British Journal of Dermatology 164, p. 1329-1334.

Marks, M., Taotao-Wini, B., Satorara, L., Engelman, D., Nasi, T., Mabey, D. C. and Steer, A. C., 2015. Long term control of scabies fifteen years after an intensive treatment programme. PLoS neglected tropical diseases 9, p. e0004246.

McCarthy, J. S., Kemp, D. J., Walton, S. F. and Currie, B. J., 2004. Scabies: more than just an irritation. Postgraduate Medical Journal 80, p. 382-387.

Monsel, G., Delaunay, P., Chosidow, O., and Oxford., -. 2016. Arthropods. in In, C. D., Griffiths, C. E. M., Barker, J., Bleiker, T. and Chalmers, R., (eds.) Rook's Textbook of Dermatology,Oxford. pp. 39-45.

Mounsey, K. E. and McCarthy, J. S., 2013. Treatment and control of scabies. Current Opinion in Infectious Diseases 26, p. 133-139.

Mutiara, H. and Syailindra, F., 2016. Skabies. Jurnal Majority 5, p. 37-42.

Paramita, K. and Sawitri, S., 2015. Profile of Scabies in Children. Berkala Ilmu Kesehatan Kulit dan Kelamin 27, p. 41-47.

Romani, L., Steer, A. C., Whitfeld, M. J. and Kaldor, J. M., 2015. Prevalence of scabies and impetigo worldwide: a systematic review. The Lancet infectious diseases 15, p. 960-967.

Strong, M. and Johnstone, P. (2010) Interventions for treating scabies (Review), The Cochrane Collaboration. in: Wiley Publishers. 
Swe, P. M., Zakrzewski, M., Kelly, A., Krause, L. and Fischer, K., 2014. Scabies mites alter the skin microbiome and promote growth of opportunistic pathogens in a porcine model. PLoS neglected tropical diseases 8, p. e2897.

Thomas, J., Peterson, G. M., Walton, S. F., Carson, C. F., Naunton, M. and Baby, K. E., 2015. Scabies: an ancient global disease with a need for new therapies. BMC Infectious Diseases 15, p. 1-6.

Walton, S. F. and Currie, B. J., 2007. Problems in diagnosing scabies, a global disease in human and animal populations. Clinical Microbiology Reviews 20, p. 268-279. 